\title{
Points, lines and surfaces in the construction of campus culture \\ Zhechun Ren ${ }^{1, \mathrm{a}}$, Ronghua $\mathrm{Ju}^{2, \mathrm{~b}, *}$ and Xiaoxiao Wang ${ }^{3, \mathrm{c}}$
}

\author{
${ }^{1,3}$ College of Politics \& International Relations, Shandong Normal University, Jinan, \\ China \\ ${ }^{2}$ College of Economics \& Management, China Agricultural University, Beijing, China \\ a renzhechun2008@163.com, ${ }^{\mathrm{b}}$ juronghua@aliyun.com, ${ }^{\mathrm{c}}$ wangxiaoxiao1989@126.com \\ * Corresponding author
}

\begin{abstract}
Construction of campus culture (CCC) should follow the core value system of socialism and adopt the scientific methodology which is from "points" to "lines" and from "lines" to "surfaces". It should persist in the pragmatic spirit which pays attention to "points", the dynamic development philosophy which regards "lines" as routes, the wide horizon which regards "surfaces" as destinations. To completely push forward campus culture development, "points" should be of individual character, "lines" should be extended and "surfaces" should be broadened.
\end{abstract}

Keywords: Construction of campus culture; Points, lines and surfaces; Core value system of socialism

\section{Introduction}

What kind of development students can get depends largely on the cultural atmosphere of the campus they stay. The construction of campus culture (CCC) is also an important way to build harmonious campus, enhance educational contents and promote sustainable development of education. The CCC is inseparable from scientific methodology guidance. Due to various reasons, our reflection on CCC methodology is not deep enough. Many schools only pay attention to specific "points" of the work, ignore the coordination between "points", and the sta- tus and role of the "points" in the whole "surface". It is proved that the CCC should persist in the pragmatic spirit which pays attention to "points", the dynamic development philosophy which regards "lines" as routes, the wide horizon which regards "surfaces" as destinations. Therefore, we must start from small and local things, embody the socialism core value system in the "points" "lines" and "surfaces" of the CCC, and from "points" to "lines", "lines" to "surfaces". Only by this way, the CCC will have a major development, and the healthy and harmonious development of college students will be provided with a strong cultural leading security.

\section{Establishing "points" in the CCC and the pragmatic spirit}

Campus culture is the sum total of ideology and behavior patterns of university teaching and all its activities. It is the common value orientation of a university after a long-term development and accumulation, covers every aspect of schoolrunning thoughts, consciousness, behavior norms, achievements in teaching and education. It consists of the concept layer, system layer, activity layer and physical layer. The $\mathrm{CCC}$ in our country must reflect the core values of the socialism orientation and requirements. We must do four insists: insisting to the CCC under the guidance of Marxism theory, insisting 
to leading the CCC to the common ideal of socialism with Chinese characteristics, insisting to carrying forward the national spirit and the spirit of the times and insisting to combining with the construction of the socialism concept of honor and disgrace. So, on the one hand, the CCC is not empty, abstract, invisible, the formation of good campus cultural atmosphere must start from one and one education events and education links; on the other hand, we should reflect the socialism core value system as the "points" of the CCC, and then from "points" to "lines", from "lines" to "surfaces", to promote the development of campus culture solidly and comprehensively.

\subsection{Establishing "points" should be the ground stone of the $\mathrm{CCC}$}

The "points" of CCC are the representative activities that can reflect the ideas of the university operation. Educational philosophy is a core element of University spiritual culture, educational function is the essential function of campus culture. They decide the value and goals of university culture, and guide the system construction of modern university ${ }^{[1]}$. The "points" of CCC refer to concept points which corresponds with campus culture concept layer, system layer, activity layer and physical layer respectively and can unite the thoughts and spirit of teachers and students. It's also the core, soul and the source of development of the university culture, such as the university motto, spirit, teaching style, class spirit and so on. The "system points" of the CCC which can make students have rules to follow is a reflection of university's rule culture, such as teaching behaviors, class management norms and dormitory management specification. The "activity points" such as teaching activities, extracurricular activities, community activities, class activities and social practice activities can unite the students and teachers involved in. The "physical points" which can enable activities to carry out, such as classrooms, auditoriums, campus attractions, practice base and so on, namely the hard environment of campus construction, are the material basis of teaching and management activities. Some people said: "the CCC is too empty, and can't touch the ground." The establishment of points in the CCC makes definite answers to the questions such as what, who, where and how to do, so that the CCC could have a reliable ground stone.

\subsection{Establishing "points" should re- flect the guidance of the socialism core value system}

Among concept points, system points, activity points and physical points, the establishment of the "concept points" is most important. The socialism core value system is the inner spirit of the socialism system and the soul of life, without its guidance, the CCC will lose direction. The socialism core value system is the basic content of "concept points" in the CCC. Of course, we can't only copy the contents and expressions of the socialism core value system, but should solidify it in school motto, school spirit, teaching style and class spirit. Then through the teaching activities, extracurricular activities, community activities, class activities held in physical points, such as the classrooms, auditoriums, campus facilities, practice base, we can make the connotation of "concept points" become the majority of teachers and students' spirit nutrition, nurturing the mind, perfecting their personality. 


\subsection{Establishing "points" should be based on each individual school's condition and the characteristics of college students}

The characteristics of individual university should be made clear. Through establishing the cultural "points", we can promote the overall development of the university and every aspect of campus culture work effectively. Second, college students' psychological needs and characteristics must be considered. For policymakers and organizers of the $\mathrm{CCC}$, they should answer the following questions: who on earth do you serve for? What is the best reason you let him participate in? They should realize that "peopleorientation" is "student-orientation" in the $\mathrm{CCC}$. That is, the establishment of $\mathrm{CCC}$ "points" must fit into the thinking and the need of college students, bring the direct and indirect spirit harvesting to college students. Thirdly, the establishment of CCC "points" should have personality, inside information and its own style. The well-known and same-style contents and activities can't go deeply into the deeper level such as people's spiritual world potential stimulation and the realization of the life value, and so on. It is also impossible to play the influence function of the culture. The "points" with different personalities reveal the rich connotation of CCC, echoes with students' rich inner heart demand from different angles and levels.

In short, the selection and determination of the CCC "points", is a deep Kung $\mathrm{Fu}$, not a product of a brainstorm of decision makers and organizers. It contains a profound insight of the target group, a clear understanding of resources, a deeply understanding of specific cultural activities.

\section{Extending "lines" and the concept of dynamic development}

The establishment of CCC "points" is only the beginning of the $\mathrm{CCC}$, far from all of the CCC. The richness of campus culture atmosphere and the internalization of the core value system of socialism never can be achieved by putting forward a slogan, organizing an activity or holding a lecture. Extending "points", from "points" to "lines", introducing the concept of dynamic development, and making the "points" inherited and traditional, is one of the important measures for doing the real good in the CCC.

\subsection{Only by extending "points" to "lines" can effects be sustained}

What is the CCC "line"? On the one hand and from the horizontal view, it refers to the mutual support between different culture construction "points" and coordination between the teaching activities, extracurricular activities, community activities, classes activities, social practice activities. On the other hand, from the vertical perspective, it refers to any one of the cultural construction "points" itself should become a crayon as time goes by, extending from the "points" to "line" and drawing a rainbow. Here, we mainly talk about the latter. For example, the significance of school motto should not be issued on the shelves. Motto education should be adhered on each session of students in a variety of ways. This "concept points" should be transformed into a red line of keeping pace with the times to play the durable role. For example, setting up a forum should not end up with occasionally making one or two lectures, it should be held on a regular basis and form a series. 


\subsection{Only by extending "points" to "lines" can "bright spots" be formed}

Boutiques or "bright spots" can virtually reflect the creativity of the $\mathrm{CCC}$, it not only enhances the university cultural taste, deeply influence the development of students, but also is a "cultural card" which shows the style and the comprehensive strength of a university. Where do "bright spots" come from? It is the persistence in the work of cultural construction "points", to do it intensively and carefully, and hold on to the last.

\subsection{Extending "points" to "lines" can make campus culture internalize as teachers' and students' mental quality and exteriorize as their behavior}

The culture internalized in the mind, exteriorized as shape, needs to experience a process of recognition, cognition and identification, only identification contributes to commitment. This will rely on long-term and repeated influence and education of excellent school culture. We should give full play to the initiative, enthusiasm and creativity of teachers and students, and actively explore new ideas, new methods of CCC the new circumstance; make a scientific planning, regard the $\mathrm{CCC}$ as a long-term project, strengthen the investment, arrange a certain proportion of funds for the CCC every year; strengthen the inspection on the CCC and develop evaluation mechanism of CCC, conduct annual appraisal recognition. In one word, patience is needed, it is not the quick buck.

\section{Extending the CCC "surface" and the wide horizon}

The CCC should form the "surface". The CCC "surface" refers to the characteristic orientation of campus culture, the whole and comprehensive grasp on measures. The CCC should be considered from the macro perspective of nation, times and society. From the system theory perspective, maximizing the effects of the "surface" should be the highest purpose of campus culture development. In the practice of CCC, due to neglecting the development and the overall understanding of "surface", and the common pursuit of the university spirit, many universities can't keep up with the pace of the times.

\section{1. "Points" should be oriented with "surface" vision}

Do the work of the small "point", but can't be constrained in "point" vision. From the point of view of cultural holographic theory, every part of the culture system contains the information of the cultural system as a whole, thus every part of the cultural system is the epitome of the whole. Therefore, the establishment of culture "points" can't be separated from the understanding and grasp of the "surface". As for the establishment of the CCC "points", there exists the problem of the endless attention to trees at the expense of forests in many universities, they didn't further excavate the broader connotation it contains and reveals the significance of the "surface", "points" became isolated, so that there is a long distance from the integral requirements of the CCC. Specifically speaking, with "surface" vision to orient the development of campus culture means realizing the whole-staff-participation, letting everyone of teachers and students become a "participating point", "luminous point" and "benefited point" in the $\mathrm{CCC}$, and not only giving full play to the maximum potential of each person, but also constantly improving everyone's cultural quality. 


\section{2. "Lines" should be oriented with "surface" vision}

Where do cultural construction "lines" extend to? How to extend? This requests an answer from the cultural construction "surface". An open mind and far-reaching vision in the ideology and methodology don't deny the pragmatic spirit and working mode which pays attention to "points". As long as we establish a farreaching time and space coordinate, there will be no confliction but a complementary relationship and mutual promotion between the methods of "points" and "surfaces". Without "surface" vision, the extension of "lines" would be blind, the campus culture development way will be narrower and narrower, and the vitality of campus culture will be curbed. Only locating the specific activities with "surface" vision can we make the campus culture "points" and "lines" become organic parts of "surface", possess biggest transcendence and radiation force.

\subsection{Locating the cultural "surface" within the national and world cul- ture "surface" vision}

The situation of individual university is the foundation. However, the development of individual university culture also should be beyond the individual perspective, possess magnanimity to absorb everything, not be self-enclosed or an anachronism, lack of deep sense of historical mission and the future prospect of consciousness. On the one hand, the campus culture must penetrate into the Chinese traditional cultures, inherit the rich cultural traditions, and flow into the sea of national culture as a destination. On the other hand, in the broad space-time coordinate, the campus culture will realize the leap from individual confirmation to the common blending.

\section{Conclusion}

In one word, "culture is an important foundation and the blood of a university for survival and development, is also an important symbol and feature of individual universities." ${ }^{,[2]}$ The campus culture is the solid spiritual foundation of modern university core competitiveness. Through the innovation of campus culture, the university can meet the reform of the education environment and the complicated and changeable social environment, and play an active leading role in the university's reform. In the practice of the CCC, only giving an overall view about the "points", "lines" and "surfaces", considering coordinately and advancing reasonably, can the university take on the due cultural mission and education responsibility.

\section{References}

[1] J. Ning "About the role of the university culture"[J], Guangming Daily, $2011,8.28$, the $7^{\text {th }}$ edition

[2] G. Yuan, "Enhancing the study of university cultural and promoting the construction of university culture", University education in China, 2002 (10) 